\title{
Toxicity of Hyperbaric Oxygen to Yeasts Displaying Periodic Enzyme Synthesis
}

\author{
By G. D. GIFFORD* AND G. G. PRITCHARD \\ Department of Botany, University of Exeter
}

(Accepted for publication 2 January 1969)

\begin{abstract}
SUMMARY
Exponential cultures of Saccharomyces cerevisiae and Candida utilis exposed to oxygen at ten atmospheres did not undergo any further cell division during treatment. All cells ultimately died when the treatment was prolonged for several days. Populations survived considerably longer with ethanol as a carbon source than with glucose. Stationary-phase populations were more resistant than exponentially-growing populations. The cell cycle of $S$. cerevisiae shows two points of resistance to oxygen toxicity which corresponded to two periods of catalase synthesis in air. These results are attributed to periodic synthesis of protective enzymes.
\end{abstract}

\section{INTRODUCTION}

Bacillus subtilis and Escherichia coli continue growth under oxygen at Io atmospheres and survival depends on the physiological state of the organisms at the time of pressure increase (Gifford, 1968). It was suggested that only cells in which there is an active synthesis of catalase at the time of pressure increase survive: in such cells a high catalase level will be maintained throughout the cell cycle since, in bacteria, induced enzyme synthesis can occur throughout the cycle (Masters, Kuempel \& Pardee, 1964; Kuempel, Masters \& Pardee, I965; Masters \& Donachie, 1966). This paper describes the effect of high pressure oxygen (HPO) on cultures of Saccharomyces cerevisiae, an organism known to display periodic enzyme synthesis (Halvorson et al. 1966) and on Candida utilis.

\section{METHODS}

Yeast strains. Saccharomyces cerevisiae E 8 and Candida utilis E I35 were obtained from the culture collection of the Department.

Media and cultivation. Cultures were maintained on malt agar at $25^{\circ}$. Cultures for HPO treatment were grown at $25^{\circ}$ on either liquid glucose + peptone medium ( $\mathrm{I} \%$ $(\mathrm{w} / \mathrm{v})$ glucose, $0.5 \%(\mathrm{w} / \mathrm{v})$ peptone, mineral salts) or, in the case of Candida utilis, glucose + nitrate medium ( $\mathrm{I} \%(\mathrm{w} / \mathrm{v})$ glucose, $0.5 \%(\mathrm{w} / \mathrm{v})$ sodium nitrate, mineral salts). In experiments using various carbon sources the cells were sedimented by centrifugation after an appropriate growth period and resuspended in fresh medium containing $\mathbf{I} \%$ or $3 \%(\mathrm{w} / \mathrm{v})$ glucose or $\mathrm{I} \%(\mathrm{v} / \mathrm{v})$ ethanol or glycerol as the carbon source. Media used in the synchronization procedure were the starvation medium of Williamson \& Scopes (1960) and the normal growth medium without glucose.

Catalase determination. Cells for catalase determination were sedimented by centrifugation, resuspended in $3 \mathrm{ml}$. of acetone for $30 \mathrm{~min}$., then centrifuged down and

* Present address: Unilever Research Laboratory, Colworth House, Sharnbrook, Bedford. 
resuspended in $3 \mathrm{ml}$. of $0.05 \mathrm{M}$-phosphate buffer $(\mathrm{pH} \mathrm{6.8)}$. The catalase activity of this suspension was determined by the method of Herbert (I954).

Synchronization procedure. Saccharomyces cerevisiae was grown in $300 \mathrm{ml}$. of medium, containing glucose as carbon source, and harvested in the late exponential phase of growth. The larger cells were selected from the population by centrifugation in $15 \%(\mathrm{w} / \mathrm{v})$ mannitol, resuspended in $25 \mathrm{ml}$. of starvation medium (Williamson \& Scopes, I960) and shaken at $25^{\circ}$ for $12 \mathrm{hr}$. The cells were then sedimented by centrifugation, washed and resuspended in $25 \mathrm{ml}$. of growth medium with no added carbon source and placed under oxygen at $5 \mathrm{~atm}$. for $\mathrm{I} 2 \mathrm{hr}$. It will become evident from the ensuing results and discussion that the deep stationary-phase culture obtained from the starvation procedure was almost entirely resistant to an HPO treatment of this duration. The oxygen treatment provided a relatively rapid and specific means of removing any cells which were out of phase with the majority of the population since only these cells would be sensitive to HPO treatment. Following release of pressure the cells and medium were inoculated into $300 \mathrm{ml}$. of fresh medium, with glucose as carbon source, in a batch culture vessel. To eliminate, as far as possible, any after effects of the HPO treatment, synchronized cultures were allowed to grow for at least $5 \mathrm{hr}$ before taking samples for the study of enzyme activity or survival under HPO.

Cell counts. Total counts were made with a Helber counting chamber $0.02 \mathrm{~mm}$. deep, with Thoma ruling. Cells were counted according to the criteria of Williamson \& Scopes (1960).

Viable counts. Survival, following HPO treatment, was determined by dispensing, in triplicate, $0.2 \mathrm{ml}$. samples of serially diluted culture on malt agar plates. Colonies were counted after $36 \mathrm{hr}$ incubation at $25^{\circ}$.

Pressure vessels. Cultures were subjected to pressure in steel pressure vessels similar to those described by Caldwell (1956).

\section{RESULTS}

Survival of Saccharomyces cerevisiae and Candida utilis cultures subjected to HPO. Exponentially-growing cultures of both organisms were sedimented by centrifugation, resuspended at a suitable concentration in media containing different carbon sources and placed on a shaker at $25^{\circ}$ for $2 \mathrm{hr}$ to allow the cells to adapt to the new media. Samples (3 ml.) of cell suspension were then dispensed into $100 \mathrm{ml}$. conical flasks, placed in pressure vessels and subjected to oxygen at Io atm. Survival was determined after various times of treatment (Fig. I, 2). In no case was there any increase in cell numbers under HPO. Death of the populations occurred gradually, over a number of days in some cases. Both yeast populations survived for a considerably longer period with ethanol than with glucose. In the case of Candida utilis survival with glycerol was similar to that with glucose.

Resistance of various stages of the cell cycle of Saccharomyces cerevisiae to HPO. Samples $(5 \mathrm{ml}$ ) were taken at intervals during the growth of a synchronous culture, dispensed into $100 \mathrm{ml}$. Erlenmeyer flasks and rapidly exposed to oxygen at Io atm. In one experiment (Fig. 3a) samples were taken at $20 \mathrm{~min}$. intervals and subjected to HPO for I $6 \mathrm{hr}$. In the second experiment (Fig. $3 b$ ) samples were taken at $12 \mathrm{~min}$. intervals and subjected to HPO for $24 \mathrm{hr}$. After release of pressure survival was determined by plate counts. 
The greatest capacity for survival was found in cells which had just completed division, virtually all the cells from a population at this stage of the cell cycle surviving the $24 \mathrm{hr}$ exposure. A second, much smaller, survival peak was observed to occur just before, or concurrent with, the onset of budding. A maximum survival of $17 \%$ was recorded for samples taken from this region though it was generally much lower.

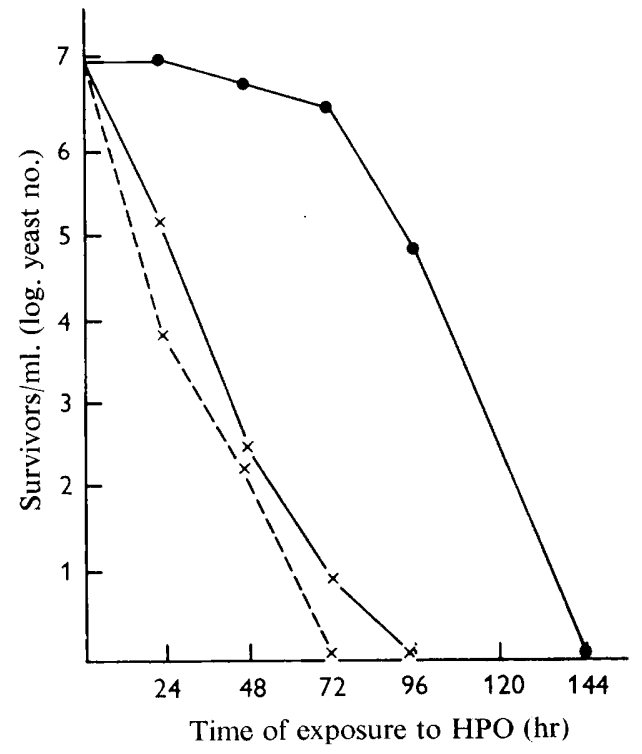

Fig. I

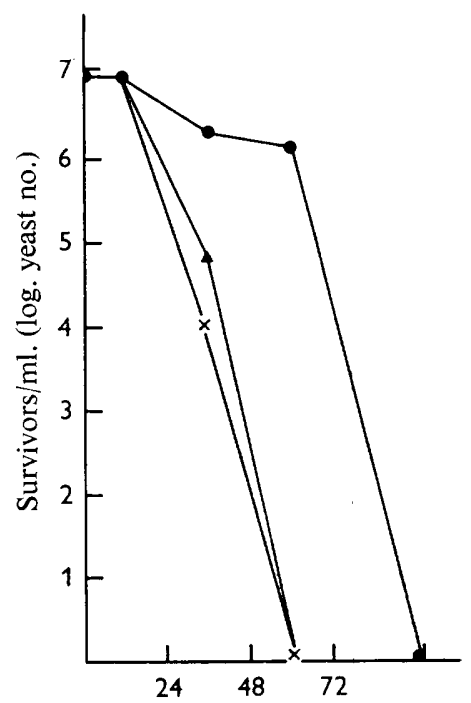

Time of exposure to HPO (hr)

Fig. 2

Fig. 1. Survival of Saccharomyces cerevisiae exposed to high pressure oxygen on media containing various carbon sources. $x-1, \mathrm{r} \%(\mathrm{w} / \mathrm{v})$ glucose; $\times--\times, 3 \%(\mathrm{w} / \mathrm{v})$ glucose; $-\mathrm{I} \%(\mathrm{v} / \mathrm{v})$ ethanol.

Fig. 2. Survival of Candida utilis exposed to high pressure oxygen on media containing various carbon sources. $\times-\times, \mathrm{I} \%(\mathrm{w} / \mathrm{v})$ glucose; $\boldsymbol{\Delta}-\mathbf{\Delta}, \mathrm{I} \%(\mathrm{v} / \mathrm{v})$ glycerol; $\longrightarrow, \mathrm{I} \%$ $(\mathrm{v} / \mathrm{v})$ ethanol.

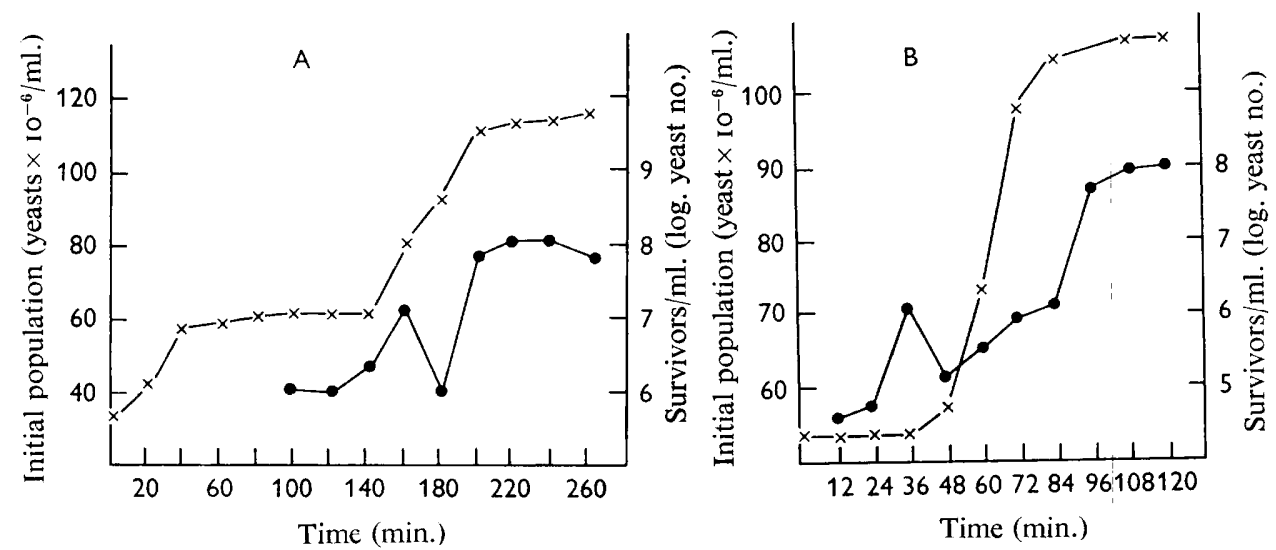

Fig. 3. Survival of Saccharomyces cerevisiae exposed to high pressure oxygen at different stages of the cell cycle. (a) Samples taken at $20 \mathrm{~min}$. intervals and exposed to HPO for I $6 \mathrm{hr}$. (b) Samples taken at 12 min. intervals and exposed to HPO for $24 \mathrm{hr} . \times-\times$, Cell numbers of initial population; - survival following HPO treatment. 
It should be noted that survival is plotted on a log. scale so that the pre-division increase in survival, relative to the samples on either side, is considerable. This predivision survival peak was noted in three other experiments.

Catalase synthesis in Saccharomyces cerevisiae in relation to the cell cycle. Samples were taken at ro min. intervals during the growth of a synchronous culture of Saccharomyces cerevisiae and the catalase activity determined (Fig. 4). Two peaks of activity were observed, one immediately before division, the other soon after. A considerable decrease in activity was observed during division and there was little increase in the total activity with increasing cell numbers.

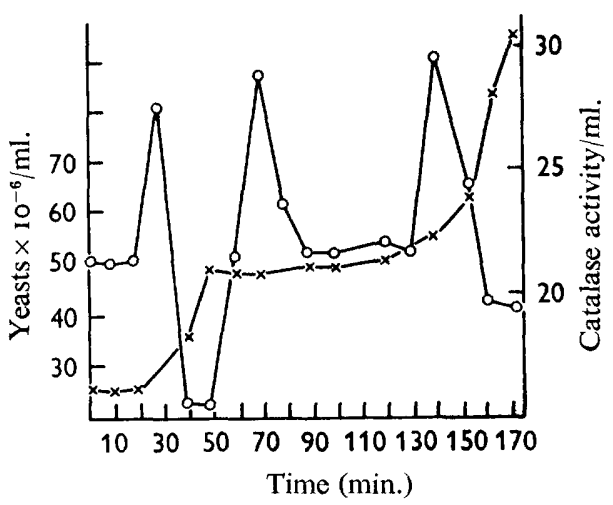

Fig. 4

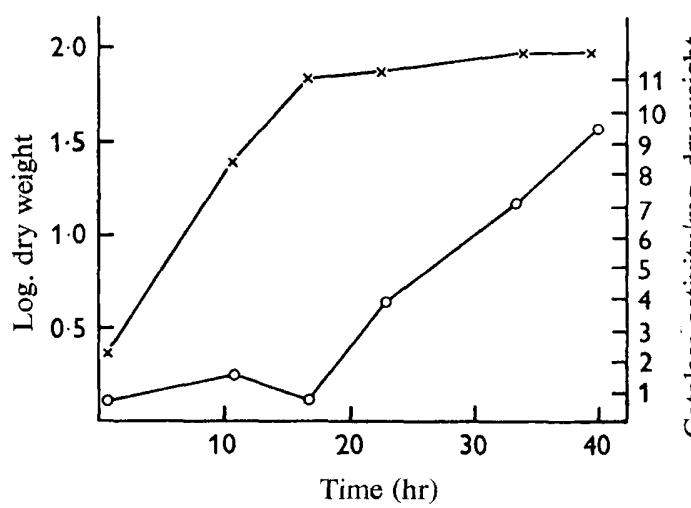

Fig. 5

Fig. 4. Catalase activity of Saccharomyces cerevisiae in relation to the cell cycle. $\mathrm{O}-\mathrm{O}$, Catalase activity; $\times-\times$, cell numbers.

Fig. 5. Changes in catalase activity during the growth of Candida utilis. $\times-\times, \log$, dry weight; $\mathrm{O}-\mathrm{O}$, catalase activity.

Effect of cell age on survival and catalase activity of Candida utilis subjected to HPO. The catalase activity, per cell, of stationary-phase cultures was many times higher than that of exponential-phase cultures (Fig. 5). Therefore it was of interest to determine the relative length of time of survival of cultures from these two stages when subjected to HPO.

Exponential-phase cultures of Candida utilis were harvested after 6 hr growth at $25^{\circ}$; stationary-phase cultures after $27 \mathrm{hr}$ growth. The cells were sedimented by centrifugation and resuspended in either $\mathrm{I} \%(\mathrm{w} / \mathrm{v})$ glucose + salts or $\mathrm{I} \%(\mathrm{v} / \mathrm{v})$ ethanol + salts medium. The concentration of the stationary-phase cultures was adjusted by dilution to that of the exponential-phase cultures since it has been found, during the course of these studies, that the duration of survival of cells in liquid suspension is affected by population density. The rate of build-up of dissolved oxygen in the culture will be slower at a high population density than at a low density.

Samples $(5 \mathrm{ml}$.) of each of the cell suspensions were pipetted into sterile Petri dishes and placed in pressure vessels. They were subjected to ro atm. oxygen and opened at various intervals to determine survival and catalase activity (Fig. 6). Stationary-phase cultures survived longer than exponential cultures on both media and survival on ethanol was greater than on glucose. Although catalase activity in exponential-phase cultures was much lower than that of stationary-phase cultures, in both cases there was an increase in catalase activity of cells on the ethanol medium in 
response to HPO treatment during the first $4 \mathrm{hr}$. On the glucose medium there was no such increase and catalase activity declined immediately.

Similar results were obtained with Saccharomyces cerevisiae.
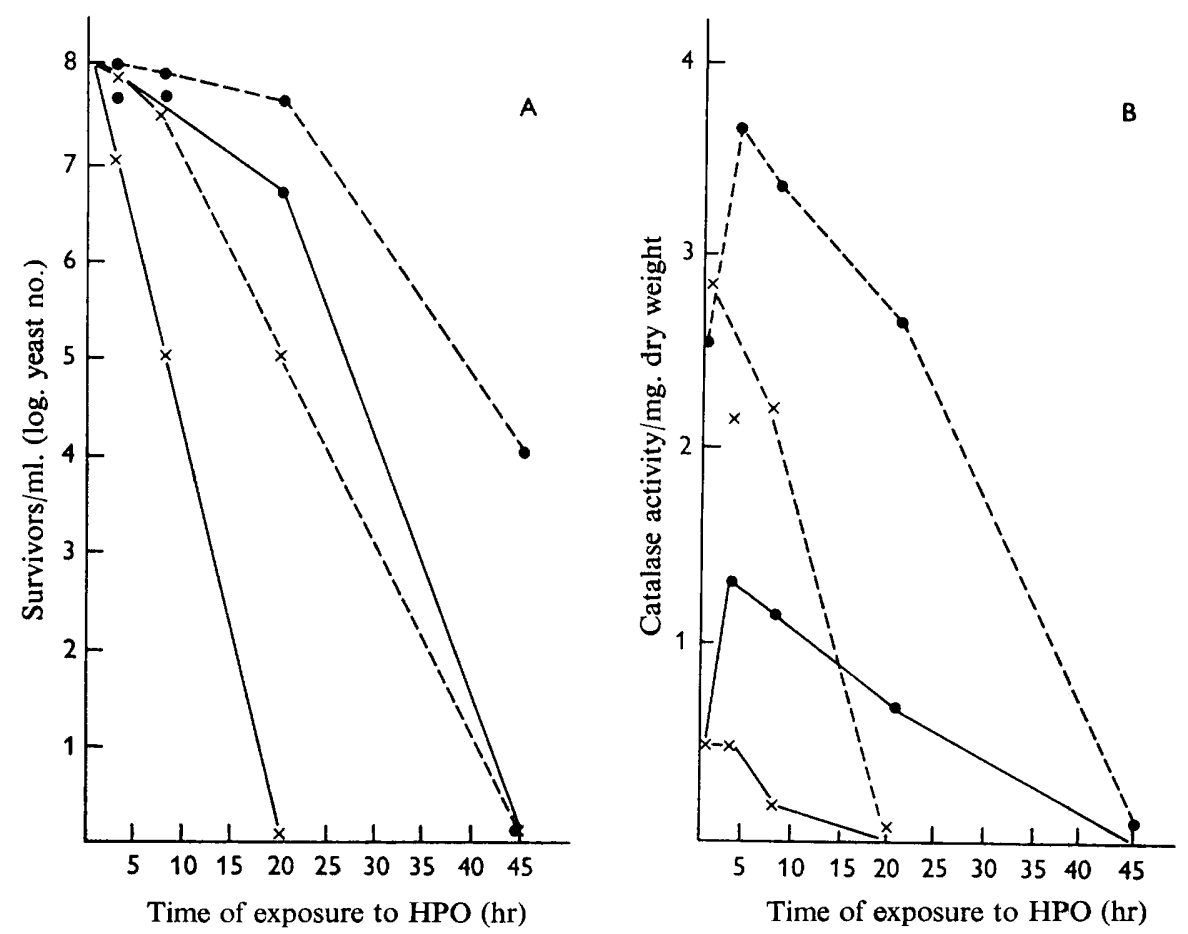

Fig. 6. (a) Survival, (b) catalase activities of exponential- and stationary-phase cultures of Candida utilis exposed to high pressure oxygen on media containing different carbon sources. Exponential phase on: $\times-\times, I \%(w / v)$ glucose; $-1,1 \%(v / v)$ ethanol. Stationary phase on: $\times \ldots+\cdots, 1 \%(w / v)$ glucose; $---1 \%(v / v)$ ethanol.

\section{DISCUSSION}

The results show that there was no continuing division of yeasts under HPO, the death of an asynchronous population occurring progressively over a period of days at a rate which was influenced by the carbon source to which the cells were exposed. Exposure of samples of synchronized cultures of Saccharomyces cerevisiae to HPO has showed that there appear to be two points in the cell cycle at which this yeast showed resistance to HPO toxicity. These correspond to two periods of catalase synthesis in the cell cycle thus implicating this enzyme in the resistance mechanism (Pritchard \& Hudson, I967; Gifford, 1968). All the cells taken just after division were capable of surviving exposure to HPO for $24 \mathrm{hr}$, whereas a maximum survival of $17 \%$ was recorded for cells taken during the pre-division period of survival. This suggests that the two periods of catalase synthesis are of unequal length. Further evidence for the existence of two periods of resistance comes from the morphology of cells in a population which had been killed by exposure to HPO. Predominantly two types of cell may be seen, one bearing small buds, which represents cells which were in, or had reached, the pre-division period of catalase synthesis at the time of exposure, 
the other bearing well-developed buds. The morphology of oxygen-killed cells of Candida utilis also suggests that there are two periods of resistance in the cell cycle of this organism.

The apparently greater resistance of stationary-phase cells to HPO toxicity may be because virtually all the cells in such a population are in a state in which catalase is being synthesized, as evidenced by the marked increase in catalase at the end of the exponential phase of growth. In exponential populations a much smaller proportion of the cells will be in this condition.

The observation that yeasts die under HPO with no further division was in marked contrast to the continuing division of bacteria under HPO (Gifford, I968), though it confirmed the fungal results of Caldwell (1964) and Robb (1966). This differing response may be related to a difference in the mechanism of control of protein synthesis. In bacteria, although basal enzyme synthesis is ordered, induced enzyme synthesis may occur at any stage of the cell cycle (Masters et al. 1964; Kuempel et al. 1965; Masters \& Donachie, 1966). In contrast, induced enzyme synthesis in yeasts shows a marked periodicity which, it has been suggested, may be due to variations in the accessibility of genes to transcription during the cell cycle (Halvorson et al. 1966). Thus it follows that, in yeasts, the synthesis of catalase will be subject to this periodic inducibility. In both bacteria and yeasts exposure of a random population to HPO results in the survival of those cells possessing a high level of, or are actively synthesizing, catalase. In bacteria the continuous accessibility of genes to transcription enables those cells which survive the initial exposure to maintain a high level of catalase by further induced synthesis and hence to continue division. In yeasts the survivors of the initial exposure will also continue to progress through the cell cycle but are unable to maintain a high level of catalase once they have passed beyond the period of the cell cycle in which catalase can be synthesized. These cells will survive until the catalase activity falls to a value which permits the formation of a toxic lesion. If this lesion is established before the next period of catalase synthesis the cells will die.

Therefore, on the available evidence, it appears that the survival of yeasts under HPO is related to the state of enzyme synthesis at the time of exposure. Cells entering a major period of catalase synthesis will survive for the longest period, those between periods of synthesis will be the first to die and there will be a series of conditions in between. Death of an asynchronous population will occur over a period of days, reflecting the random physiological states of the cells at the time of exposure.

The effect of carbon source on the length of time of survival under HPO may be related to the rate of decline in catalase level during treatment with HPO. Cells die most rapidly on those substrates which allow a rapid rate of growth in air, i.e. more rapid progress through the cell cycle. Cells on such substrates will remain for a short period of time within the period of catalase synthesis, whereas on substrates supporting a slower rate of growth, such as ethanol, the cells may remain within the synthetic period sufficiently long to allow some further synthesis of catalase, thus enhancing survival. The immediate decline of catalase activity of asynchronous cells on glucose and the brief rise in catalase activity of cells on ethanol support this suggestion. A similar effect of carbon source upon survival has been observed in other fungi (Dr S. Ahmed, personal communication).

This work was supported by a grant from the Science Research Council. 


\section{REFERENCES}

Caldwell, J. (1956). Studies in the respiration of apple at various pressures of oxygen. J. exp. Bot. 7, 326.

CaldWEll, J. (1964). Effect of high pressures of pure oxygen on tissues. Nature, Lond. 201, 514.

GIFFORD, G. D. (1968). Toxicity of hyperbaric oxygen to bacteria in relation to the cell cycle and catalase synthesis. J. gen. Microbiol. 52, 375 .

Halvorson, H. O., Bock, R. M., Tauro, P., Epstein, R. \& La Berge, M. (1966). Periodic enzyme synthesis in synchronous cultures of yeast. In Cell Synchrony. Ed. by I. L. Cameron and G. M. Padilla. New York: Academic Press.

Herbert, D. (I954). Catalase from bacteria (Micrococcus lysodiekticus). Meth. Enzym. 2, 784.

Kuempel, P. L., Masters, M. \& Pardee, A. B. (1965). Bursts of enzyme synthesis in the bacterial cell cycle. Biochem. biophys. Res. Commun. $\mathbf{8} 8,858$.

MAsters, M. \& DONACHIE, W. D. (1966). Repression and control of cyclic enzyme synthesis in Bacillus subtilis. Nature, Lond. 209, 476.

Masters, M., Kuempel, P. L. \& Pardee, A. B. (1964). Enzyme synthesis in synchronous cultures of bacteria. Biochem. biophys. Res. Commun. 15, 38.

Pritchard, G. G. \& Hudson, M. A. (1967). Changes in catalase activity in higher plants and fungi treated with oxygen at high pressure. Nature, Lond. 214, 945.

RoвB, S. M. (1966). Reactions of fungi to exposure to Io atmospheres pressure of oxygen. J. gen. Microbiol. 45, 17.

Williamson, D. H. \& Scopes, A. W. ( 1960 ). The behaviour of nucleic acids in synchronously dividing cultures of Saccharomyces cerevisiae. Expl Cell Res. 20, 338. 
